\title{
Nanobodies and their medical applications
}

\author{
H. Boulenouar ${ }^{1,2}$, Y.Amar ${ }^{1,3}$, N. Bouchoutrouch ${ }^{1}$, M.E.A. Faouzi ${ }^{2}$, \\ Y. Cherrah ${ }^{2}$ and H. Sefrioui ${ }^{1}$ \\ ${ }^{1}$ Medical Biotechnology Center, Moroccan Foundation for Advanced \\ Science, Innovation \&Research, Rabat, Morocco \\ ${ }^{2}$ Laboratoire de Pharmacologie et Toxicologie, Faculté de Médecine et de \\ Pharmacie Rabat, Université Mohammed V, Rabat, Morocco \\ ${ }^{3}$ Laboratoire de Biologie des Pathologies Humaines, Faculté des Sciences \\ Rabat, Université Mohammed V, Rabat, Morocco
}

Corresponding author: H. Sefrioui

E-mail: h.sefrioui@mascir.com

Genet. Mol. Res. 19 (1): gmr18452

Received July 16, 2019

Accepted March 11, 2020

Published March 26, 2020

DOI http://dx.doi.org/10.4238/gmr18452

ABSTRACT. Nanobodies (Nbs) are mini antibodies 10 times smaller than conventional antibodies. They constitute a new class of antibodies devoid of light chains. Their paratope consists of a single variable domain "VHH" (heavy chain variable domain) formed by a single peptide chain. Nevertheless, Nbs maintain the same repertoire of diversity and affinity characteristics as conventional antibodies. Because of their high specificity, small size, and low production cost, Nbs are emerging progressively as a potential alternative to overcome the limitation of conventional antibodies in targeted therapy. Indeed, the therapeutic spectrum of Nbs has been confirmed in animal models and human clinical trials. The present review provides a summary of the technological advances in the production of $\mathrm{Nbs}$ and their potential targeted therapeutic biomarkers over the past 10 years.

Key words: Nanobodies; Biomarkers; Therapeutic applications; Production Techniques; Conventional antibodies

\section{INTRODUCTION}

Advances in immunotherapy and molecular biology are the basis for the development and production of therapeutic monoclonal antibodies. These conventional antibodies have gradually invaded the pharmaceutical sector and the world of targeted therapy through their use 
in oncology, neurological and inflammatory diseases, among others (Pérol and Arpin, 2011). Besides, the leading pharmaceutical companies continue to be interested and committed to the development of novel monoclonal antibodies (Andersen and Krummen, 2002). However, due to their high production cost and low penetration rate into certain tissues (large size), their therapeutic use remains limited. Thus, in the case of solid cancers, which account for $85 \%$ of cancers, only three monoclonal antibodies have been accepted for clinical use (Shemi et al., 2015).

Other successful studies have demonstrated the possibility to obtain affinities from picomolar to nanomolar using only the variable domain (VHH) of some antibodies from camelids and cartilaginous fish (Hamers-Casterman et al., 1993; Greenberg et al., 1995; Dooley et al., 2003) named "Nanobodies" (Nbs). The Nbs are known as heavy chain antibodies (HCAb) (Siontorou 2013)or single domain antibodies (sdAb) (Comor et al., 2017). Given the lack of the light chain, Nbs antigen binding sites carry a single variable domain called VHH for Camelidae and vNAR for sharks (Flajnik et al., 2011; Griffiths et al., 2013). However, while monoclonal antibodies (mAbs) rely on the immortalization of the antibody producing B-cell, most Nbs are obtained by isolating the RNA from the circulating peripheral B-cells to capture the animals immune repertoire of variable heavy domains displayed on the surface of phage. From this phage library, Nbs that binds the target of interest can be isolated and provide a unique mode of binding and recognition to the antigen-epitopes. The latter are inaccessible to conventional antibodies (Desmyter et al., 1996; Lauwereys et al., 1998; Dooley et al. 2003; Streltsov et al., 2005).

The simple structure of Nbs, their easy manipulation, therapeutic efficiency and their cost-effective production have attracted biotech companies to invest further in Nbs development (Roovers et al., 2007). Indeed, several companies have specialized in the production of Nbs including the Belgian company "Ablynx" developing Nbs from Camelidae, and the American company "GenWay Biotech" from cartilaginous fish with an ongoing clinical trials (Wolfson, 2006; Siontorou, 2013). In this review, the major focus is on the potential therapeutic activities of Nbs based on their simple structures and high affinities to specific biomarkers of viruses, inflammatory and neurodegenerative diseases as well as certain types of cancers.

\section{STRUCTURE AND PHYSICOCHEMICAL PROPERTIES OF NANOBODIES}

\section{Structure}

Conventional antibodies are mainly formed by two heavy and light chains. The heavy chain contains three constant domains $(\mathrm{CH} 1, \mathrm{CH} 2, \mathrm{CH} 3)$ as well as a variable domain $(\mathrm{VH})$. The light chain contains a constant domain (CL) which interacts with the constant domain (CH1) by a disulfide bridge and a variable domain (VL) as presented in Figure 1 (Wang et al. 2016). The therapeutic use of these antibodies remains limited due to their high molecular weight (150 kda) that hinders their penetration into certain tissues and to their strong immunogenicity with a very long half-life may lead to a toxicity risk (Saerens et al., 2008; Siontorou, 2013).

In contrast to the conventional antibodies, Nbs have a simpler monomeric structure. In fact, their structure is almost identical to conventional $\operatorname{IgG~VH}$ with four conserved FR regions surrounding the three-hypervariable CDR regions, which confers a specific recognition to the antibody (Figure 1). In CDR regions, the difference is quite remarkable and the CDR1 and CDR3 regions are moderately longer (16-18 amino acids (CDR3)) than the human VHs (9-12 amino acids). Thus, the $\mathrm{CH} 1$ domain was excised out of the mRNA by alternative splicing and 
$\mathrm{CH} 2$ and $\mathrm{CH} 3$ domains are conserved and constitute the $\mathrm{FC}$ fragment like conventional antibodies. However, the VHH domain replaces the entire IgG. Hence, the VHH small variable fragments able to bind perfectly to unique conformational epitopes owing to its long CDR3 region and its monomeric structure without the need for dimer formation, as in the case of conventional antibodies. The VHH (15 kD) domain is called "Nanobody"(Transue et al., 1998).

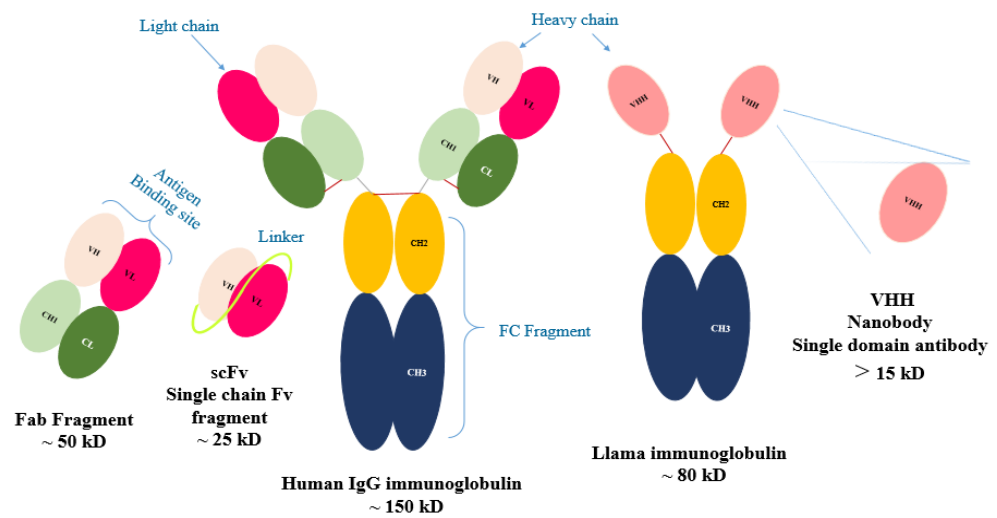

Figure 1. Conventional antibodies (Ab) carrying combination of heavy chains and light chains and camelids $\mathrm{Ab}$ with heavy chains and a single variable domain, VHH, Adapted from Muyldermans (2013)

\section{Physicochemical properties and advantages of Nanobodies}

The affinity of a $\mathrm{Nb}$ for its antigen is very strong because their interaction with their target leads to the rapid formation of a complex (Kon between 105 and $106 \mathrm{M}-1 \mathrm{~S}-1$ ) and a slow dissociation (Koff between 10-4 and 10-2 S-1) (Wesolowski et al., 2009; HassanzadehGhassabeh et al., 2013). Moreover, Nbs have a high solubility and stability that allow them to have a resistance to extreme physicochemical conditions due to their intrinsic properties and to have strong binding with the target antigen during the selection stage (Rahbarizadeh et al., 2011). In addition, the simple nature of Nbs heavy chain promotes a declination in bi- and trispecific antibodies and their resemblance to the $\mathrm{VH}$ domains of human antibodies make them little or none immunogenic.

\section{SELECTION AND PRODUCTION OF RECOMBINANT NANOBODIES}

The production process of Nbs is well controlled and takes place in several stages. In fact, many recombinant expression systems have been established and optimized for this purpose, especially in yeasts, bacteria, fungi or mammalian cells. For example, in Saccharomyces cerevisiae, expression levels of Nbs were reported to $100 \mathrm{mg} / \mathrm{L}$ in a flask under stirring and $1 \mathrm{~g} / \mathrm{L}$ using the fed-batch fermentation with a yield up to $1,3 \mathrm{~kg}$ at the scale of $15 \mathrm{~m}^{3}$ (Frenken et al., 2000; Thomassen et al., 2002).

Nanobodies are generally non-immunogenic when injected into human, as there is a strong sequence identity with the human $\mathrm{VH}$ domain. In addition, their small size ensures a rapid elimination from blood, a better elimination by the renal system and a decrease in matters of toxicity (Siontorou, 2013).

VHH engineering uses advanced and robust techniques. Indeed, Nbs library should be constructed in order to select only the ones that have successfully linked to the target antigen (Figure 2). Due to several specific applications, the immune library is the most commonly used 
and considered as an additional time effective option. Differently to the naive library, the immune library goes through a step of immunizing the camelid with the antigen of interest.

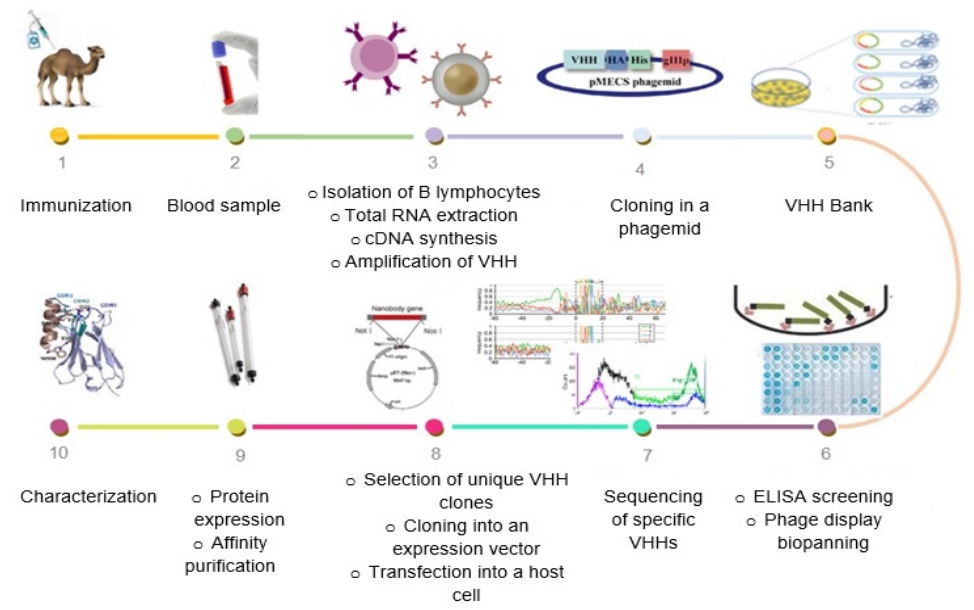

Figure 2. Traditional process of the variable domain (VHHs) production

However, the immunization step is not always possible if the injected antigen is nonimmunogenic or toxic for the camelid (Yan et al., 2015). This pathway has several advantages including somatic maturation, which consists of the selection with high antigen affinity. The blood from the camelid is then collected, the peripheral blood mononuclear cells (PBMC) harvested, and the DNA extracted. To amplify sequences coding for the VHH, the cloning strategy consist of performing two successive PCRs from cDNAs, which represent the whole $\mathrm{IgG}$ of the B-lymphocytes from the immunized Camelid. The first PCR serves to amplify the region located between the constant domain $\mathrm{CH} 2$ and the leader sequence of $\mathrm{VH}$ and $\mathrm{VHH}$ variable domains while using primers hybridizing with sequences conserved among the set of Camelid IgG isotypes. The second PCR serves to generate shorter fragments corresponding to VHH sequences. This Second PCR is also used to introduce restriction sites facilitating phageoriented cloning in order to obtain a phagemid library representing all the diversity of Nbs repertoire. Nbs specific to the target antigen will be selected and enriched (biopanning) by phage-display. Biopanning is realized on immobilized antigens by passive adsorption on a solid surface (micro titer plate), three rounds of biopanning are sufficient to enrich interesting clones. Subsequently, the ability of these Nbs to recognize the antigen is tested by ELISA, and positive clones are then sequenced to get access to the sequence of Nbs of interest. Afterward, VHH sequences will be cloned into an expression vector for the production in host cells. By including the sequence coding for the signal peptide, the protein produced can be exported to the periplasm, where oxidative conditions favor the correct folding of Nbs and the formation of disulfide bridges. After periplasmic extraction, a simple purification is generally carried out since the $6 \mathrm{His}$ tag is integrated into the expression vector which allows purification via an affinity column and then via a gel filtration. Beside this classic approach, HassanzadehGhassabeh et al. (2013) have described another strategy to generate potent Nbs and streamline their identification (Hassanzadeh-Ghassabeh et al., 2013). They mentioned the importance of Nbs immunization with more difficult targets such as receptor complexes, multipass membrane proteins or intrinsically disordered proteins. They have also highlight the advantage of implementing NGS as a deep sequencing approach to rapidly discover antigen-specific $\mathrm{Nb}$ 
sequences. In another study, Fridy et al have described an approach, which can be adapted to the development of $\mathrm{Nb}$ reagents against diverse type of proteins targets with high affinity and specificity (Fridy et al., 2014). This approach has been effective to produce and generate large repertoires of Nbs against GFP and mCherry antigens with $\mathrm{Kb}$ values into the subnanomolar range. In fact, they have demonstrated the possibility to design ultrahigh-affinity dimeric Nbs with $\mathrm{Kd}$ values as low as $30 \mathrm{pM}$.

\section{Phage Display}

The production of Nbs requires the adoption or the development of a mastered strategy with advanced techniques with high sensitivity and specificity. Among the most powerful and used techniques in Nbs production is the "Phage Display". This technique is considered as a powerful tool for high throughput screening of protein interactions (Crameri and Kodzius, 2001). Indeed, As a screening platform, Phage Display has a great importance for pharmaceutical companies in the development of new patentable entities (Rader and Barbas III, 1997; Castel and Tordo, 2009). This technique is mainly based on the exposure of the protein of interest (peptides, antibodies or other) on the surface of a bacteriophage and on the binding affinity and specificity of the protein of interest with the NH2-terminal domain of one of bacteriophage surface proteins (Souriau et al., 1998; Castel et al., 2009).

\section{Pishia pastoris expression system}

Being a methylotrophic yeast, Pishia pastoris is widely used as an expression system for the production of both intracellular and extracellular proteins with a large number of expression vectors including; pPIC9, pPIC9k, pPICZ $\alpha$, pHIL-D2, pHIL-S1, pFLD and pFLD $\alpha$, pGAPZ and pGAP (Safder et al., 2018). In fact, the Pishia expression system allows easy purification and culture with high cell densities allowing to obtain high yields of protein per liter (Daly and Hearn, 2005).

Pishia pastoris has two alcohol oxidase genes, AOX1 and AOX2. They have strong and inducible promoters. These two genes allow Pishia pastoris to assimilate methanol as a single source of carbon and energy. In fact, by using highly inducible methanol, Pishia is able to convert $30 \%$ to $40 \%$ of its weight into proteins (Näätsaari et al., 2012). The stability of the expression cassette in the yeast genome, its secretion capacity, the low levels of contaminating proteins in culture medium and the rapid growth of the yeast on inexpensive media and in fermentors, make Pichia patoris an excellent choice for the expression of heterologous proteins.

\section{THERAPEUTIC APPLICATION OF NANOBODIES}

While the use of mAbs in targeted therapy remains limited, in recent years, rapid progress has been made in the engineering and selection of VHH domains, including Nbs, for therapeutic purposes. Thus, it has been demonstrated that these Nbs have a high ability to be modified without losing their structural integrity and are compatible with a variety of high throughput screening platforms such as yeast, phages and bacteria (Ghahroudi et al., 1997; Ryckaert et al., 2010; Fleetwood et al., 2013). In addition, the robustness of Nbs, particularly those resistant to acidic $\mathrm{pH}$ and peptic proteolysis that exist in the gastrointestinal environment, have been explored for oral administration. Indeed, this modality decreases the constraints and considerably improving the comfort of the patients (Hussack et al., 2011). The major ongoing clinical trials using Nbs are summarized in Table 1. Their strong potential use is applied to 
different sectors including diagnosis and especially therapeutic medicine against certain viral infections, inflammation, neurodegenerative diseases and cancers.

Table 1. Major nanobodies in clinical trials.

\begin{tabular}{|c|c|c|c|c|}
\hline Nanobodies & Mechanism/targest & Indications & $\begin{array}{l}\text { Clinical trial } \\
\text { studies }\end{array}$ & Developer/Sponsor \\
\hline $\begin{array}{l}\text { ALX - } 0761 \\
{[69]}\end{array}$ & Anti-IL-17A/F Nanobody & Moderate to severe psoriasis & Phase 1 & $\begin{array}{l}\text { Merk KgaA, Darmstadt, } \\
\text { Germany }\end{array}$ \\
\hline $\begin{array}{l}\text { Caplacizumab } \\
(\text { ALX-0681) } \\
{[70]}\end{array}$ & Bivalent VHH against Vwf & $\begin{array}{l}\text { Treatment of acquired thrombotic } \\
\text { thrombocytopenic purpura } \\
\text { (aTTP) }\end{array}$ & Approved & Ablynx \\
\hline $\begin{array}{l}\text { ALX-0171 } \\
{[71]}\end{array}$ & $\begin{array}{l}\text { Trivalent Nanobody against } \\
\text { antigenic site II of } \mathrm{F}\end{array}$ & $\begin{array}{l}\text { treatment for acute RSV } \\
\text { (Respiratory syncytial virus) } \\
\text { infection }\end{array}$ & Phase 2 & Ablynx \\
\hline $\begin{array}{l}\text { ALX- } \\
\text { 0061 Vobarilizuma }\end{array}$ & $\begin{array}{l}\text { Nanobody against the } \\
\text { binterleukin-6 receptor (IL-6R) }\end{array}$ & & Phase $2 b$ & Ablynx \\
\hline & $\begin{array}{l}\text { Bispecific VHH targeting both } \\
\text { TNF and HAS }\end{array}$ & $\begin{array}{l}\text { Treatment of Rheumatoid } \\
\text { arthritis }\end{array}$ & Phase 2 & Taisho \\
\hline $\begin{array}{l}\text { Ozoralizumab } \\
\text { (ATN-103) [72] } \\
\text { Anti-HER2 5F7 } \\
\text { Nanobody } \\
\text { [73] }\end{array}$ & Anti-HER2 5F7 Nanobody & $\begin{array}{l}\text { Imaging of HER } 2 \text { receptors } \\
\text { expression in cancer }\end{array}$ & Phase 1 & Ablynx \\
\hline $\begin{array}{l}\text { M6495 } \\
\text { [74] }\end{array}$ & Anti-ADAMTS-5 nanobody & $\begin{array}{l}\text { Treatments for osteoarthritis, } \\
\text { protects against cartilage } \\
\text { breakdown }\end{array}$ & Phase 1 & $\begin{array}{l}\text { Merk KgaA, Darmstadt, } \\
\text { Germany }\end{array}$ \\
\hline $\begin{array}{l}\text { ALX-0962 } \\
{[72]}\end{array}$ & $\begin{array}{l}\text { Bispecific VHH targeting both } \\
\text { IgE and HSA }\end{array}$ & $\begin{array}{l}\text { Treatment of severe allergic } \\
\text { Asthma }\end{array}$ & $\begin{array}{l}\text { Preclini-cal } \\
\text { trials }\end{array}$ & Ablynx \\
\hline $\begin{array}{l}\text { ALX-0141 } \\
{[75]}\end{array}$ & Targets RANKL & $\begin{array}{l}\text { Cancer-related bone diseases, } \\
\text { osteoporosis }\end{array}$ & Phase 1 & Ablynx \\
\hline $\begin{array}{l}\text { Dekavil } \\
{[72]}\end{array}$ & scFv-IL-10 targeting Fibronectin & Treatment of inflamed tissues & Phase 2 & Philogen/Pfizer \\
\hline $\begin{array}{l}\text { ATN-192 } \\
{[72]}\end{array}$ & Trivalent bispecific VHH & $\begin{array}{l}\text { Treatment of SLE (Systemic } \\
\text { Lupus Erythematosus) }\end{array}$ & Phase 1 & Ablynx \\
\hline $\begin{array}{l}\text { DR5Nb1 } \\
{[76]}\end{array}$ & $\begin{array}{l}\text { Human DR5 (death receptor)- } \\
\text { specific Nanobody targeting } \\
\text { death receptor signaling. }\end{array}$ & $\begin{array}{l}\text { Treatment of colon and } \\
\text { pancreatic cancers, and tumor } \\
\text { xenografts. }\end{array}$ & Phase 1 & Novartis \\
\hline ALX-0651 & $\begin{array}{l}\text { Bivalent nanobody inhibiting } \\
\text { CXCR4 }\end{array}$ & $\begin{array}{l}\text { Treatment of non-Hodgkin's } \\
\text { lymphoma and multiple myeloma }\end{array}$ & Phase 1 & Ablynx \\
\hline $\begin{array}{l}\text { ALX-0081 } \\
\text { [77] }\end{array}$ & $\begin{array}{l}\text { Nanobody against against Von } \\
\text { Willebrand factor }\end{array}$ & $\begin{array}{l}\text { Treatment of acute coronary } \\
\text { syndrome and percutaneous } \\
\text { coronary intervention }\end{array}$ & Phase 2 & Ablynx \\
\hline
\end{tabular}




\section{Viral infections}

Nbs possess a simple structure and strong affinities with the potential to target numerous antigen-epitopes, which is perplexed for conventional antibodies. This makes $\mathrm{Nbs}$ useful against infectious pathogens. Indeed, Stohr et al have developed ALX-071 a trimeric $\mathrm{Nb}$ targeting the fusion protein of RSV (Respiratory Syncytial Virus). They have reported the successful of clinical trial phase 2 and the superior in vitro neutralization compared to pavilizumab, the conventional $\mathrm{mAb}$ version used to prevent the same infection (Detalle et al., 2016). Other recent study demonstrated a significant reduction of RSV with improved clinical symptoms in RSV-infected animals (Mejias et al., 2017). In the same year, Koch et al identified new Nbs neutralizing relevant HIV subtypes. Those Nbs are classified as candidates for preclinical and clinical development (Koch et al., 2017). A recent interesting study has shown Nbs contribution to antiviral treatments and prevention of DENV (Dengue virus) which is a mosquito-borne virus that infects over 50 million people worldwide annually (Morgan, 2019). Vanlandschoot et al. (2011) have described the therapeutic applications of Nbs against other viruses such as Hepatitis B virus, influenza virus, Poliovirus, Foot-and-mouth disease virus, Rotavirus and Porcine endogenous retrovirus (Vanlandschoot et al. 2011).

\section{Alzheimer Disease}

Alzheimer Disease (AD) is a chronic neurodegenerative disease characterized by specific changes that include intraneuronal and extracellular parenchymal lesion. Those changes impair social function and activities of daily living of patients (Dubois et al., 2010).

Due to their small size and the presence of hydrophilic residues in the FR2 fragment, Nbs have the capacity of crossing the blood-brain barrier and targeting the central nervous system (CNS) (Farrington et al., 2014). These characteristics make Nbs powerful therapeutic tools to consider in the fight against neurological diseases. Among these diseases, AD represents a major social issue (behavioral and neuropsychiatric changes) in which it is essential to detect biomarkers that are neurochemical indicators used to estimate the risk or the presence of this disease. Apolipoprotein E (ApoE) remains a risk factor for AD, which can lead to an excess of amyloid formation in the brain. In 2017, Xiang Ren et al developed Nbs directed against ApoE acting as immuno-detectors (Ren et al., 2017) that may have potential in clinical diagnosis and real-time monitoring of the progression of AD.

\section{Coronary Syndrome and Rheumatoid Polyarthritis}

Other $\mathrm{Nbs}$ have been tested in clinical trials phases I and II as therapeutic molecules. A major study is underway with two bivalent Nbs, ALX-0081 and ALX-0061. ALX-0081 is directed against Von Willebrand factor as an antithrombotic agent for patients with acute coronary syndrome and percutaneous coronary intervention. ALX-0061 is directed against the interleukin- 6 receptor as an anti-inflammatory agent for patients with rheumatoid arthritis. Indeed, when it is difficult to achieve desirable levels of pharmacokinetics, Nbs can be adapted to prolong the half-life in the blood to achieve high serum levels and prolonged therapeutic efficacy (Van Bockstaele et al., 2009; Ulrichts et al., 2011). 


\section{Parkinson Disease}

Parkinson's disease (PD) is a neurodegenerative disease of aging PD is characterized neurologically by tremors and uncontrolled bradykinesia due to the loss of dopamine-producing neurons in the substantia nigra (Perez et al., 2007) specifically by the misfolding and aggregation of amyloid-b proteins and alpha-synuclein (aS) (Choi and Gandhi, 2018). In autopsy, the detection of these amyloid structures in brain tissue allows an accurately diagnosis subtypes of neurodegenerative diseases (Roberts et al., 2015). Klenerman et al. (2015) has developed two Nbs; NbSyn2 and NbSyn87, which bind to the C-terminal region of aS (Roberts et al., 2015). They were able to show that both Nbs inhibit the formation of fibrS fibrils. In addition, by using single-molecule fluorescence techniques, they demonstrated that the binding of Nbs promotes a rapid conformational conversion of more stable oligomers to less stable oligomers of aS. This leads to a strong reduction of oligomers induced cellular toxicity .

\section{Cancer therapy}

Despite the successful cancer therapy of mAbs, their high production cost pushed researchers to look for more cost-effective candidates. Thus, Nbs can be the best alternative because of their low cost production and outstanding features for targeting tumors such as angiogenesis factors (VEGF family, HER-2, and EGFR) (Alibakhshi et al., 2017). They could be considered as promising tools to identify and obtain site-specific targeting. Nbs are also considered as efficient tools for cancer research as they can enable specific modulation of targets and enzymatic and non-enzymatic proteins alike (Van Audenhove and Gettemans, 2016).Indeed, Nbs can be used to block ligand-receptor interactions as it has been shown in a recent study by Salvador et al where $\mathrm{Nb} 1$ and $\mathrm{Nb} 6$ were able to block the EGF-EGFR (Guardiola et al., 2018) as well as the anti-EGFR Nbs liposome for blocking the EGFR on the tumor cell surface (Allegra et al., 2018). In addition, EGFR and HER-2 Nbs has also the potential for targeting cancer cells as presented in Tao Zou's et al study using HER-2 Nb for functionalizing PEG-b-Polycaprolactone polymersomes that could target HER-2 over expression in breast cancer (Zou et al., 2015). Other studies have tested four Nbs (Nb22, $\mathrm{Nb} 23, \mathrm{Nb} 35$ and, $\mathrm{Nb} 42$ ) providing their potential to inhibit endothelial cell proliferation (Kazemi-Lomedasht et al., 2015). Whereas, other multi-specific Nbs binding multiple targets with only one $\mathrm{Nb}$ molecule are under development (DeFrancesco, 2017). In addition, some multivalent Nbs (Table 1) are used as radionuclide vehicles in radioimmuno-therapy which is becoming more and more an interesting strategy for cancer treatment (Dekempeneer et al., 2016). Finally, Nbs have also emerged as probes for non-invasive imaging of tumor cells for breast cancer (Du et al., 2018) and colon carcinoma (Vaneycken et al., 2011).

\section{Imaging and antibody chip}

The development of Nbs for imaging purposes has not only involved the fusion with fluorescent proteins but also with coupling to radio-elements (Vaneycken et al., 2011)and fluorochromes (Wang et al., 2015). The principle is to fuse the $\mathrm{Nb}$ to a fluorescent protein, expressed in mammalian cells. The goal is to label antigens in vivo at 
different subcellular compartments throughout the cell cycle (Rothbauer et al., 2006). Further, Nbs can be used for dynamic imaging at very high resolution (Albrecht et al., 2015, Platonova et al., 2015).

Fluorescent protein-fused Nbs named "chromobodies" can serve as in vivo tracers and versatile tools to study dynamics and cellular localization of proteins, the abundance of cellular compounds and the dynamics of their interactions with other molecules (Traenkle and Rothbauer, 2017). Additionally, the easy modification of Nbs allowed their fusion to a variety of fluorescent molecules, as well as their chemical coupling to branched gold nanoparticles that has strongly produced photo-thermal therapeutic agents which target antigens during the light irradiation (Wang et al., 2016). In other study, it was discussed that NP-based immuno-sensors provide good results with a promising sensitivity and reproducibility (Farka et al., 2017). The same study has described the role of nanopaticles in immuno-sensing as a promising approach for fast, low-cost, and accessible detection of trace prognostic biomarkers, drugs, microbial pathogens, toxins and environmental pollutants.

Since Nbs have the ability to penetrate the blood-brain barrier due to their small size, which allows them to be removed quickly from kidneys. This gives rise to images with an excellent signal/noise and allows an interpretation after a few hours only a posteriori of the injection of a marker. Unlike conventional antibodies that take between 2 and 4 days after injection to interpret the image. Moreover, the size of Nbs is much higher than the threshold of renal clearance causes their accumulation in the liver, so their half-life in the blood can go up to 10 days. In addition, the Fc domain of Nbs interacts with cell surface receptors, further increasing their retention in the bloodstream and their background noise in imaging (Huang et al., 2010; Hemmer, 2015).

Other applications of Nbs in imaging are in the cancer field. For example, in the case of HER2 positive cancers (breast, gastric and ovarian cancers), Ganesan et al. have evaluated a noninvasive imaging procedure that could assess the expression of HER2 in primary and metastatic lesions as well. This method called "Immuno-PET"could be a valuable tool for optimizing HER2-targeted therapy. The concept in this study is to use ${ }^{18} \mathrm{~F}$ labeled Nbs as probes for evaluating HER2 status by 'Immuno- PET'. For that purpose, they have labeled the "5F7 Nb" with the ${ }^{18}$ Fand they demonstrate that the ${ }^{18}$ F-labeled antiHER2 Nbs are the adequate tracers for the evaluation of HER2 expression (Vaidyanathan et al., 2016). Another study has shown that the labeled" $2 \mathrm{Rs} 15 \mathrm{dNb}$ " with ${ }^{68} \mathrm{Ga}$ enabled high contrast PET-imaging of HER2-positive breast cancer (Zhou et al., 2017). Due to their fast extravasation, good tumor penetration and quick renal clearance of excess tracer, Nbs allow sensitive imaging of target tissue within a short time after injection instead of several hours when using conventional mAbs.

Ultimately, the simple single-domain structure and the enhanced stability make $\mathrm{Nbs}$ potential candidates for the rapid development with high-density of antibody chips (Wang et al., 2016).

\section{CONCLUSIONS}

Nanobodies represent a new generation of mini-antibodies with particular advantages of size, structure, affinity, stability, and ease of production on a large scale. They are considered an effective therapeutic alternative to conventional mAbs that often 
have limited efficacy and high production cost. Indeed, several Nbs are already in clinical trials phases I or II, especially against cardiovascular, neurodegenerative or autoimmune diseases.

These properties and advantages make Nbs powerful tools that can be used in many fields, including diagnostics, cellular and medical imaging, and finally targeted immunotherapy. Only the future can confirm if $\mathrm{Nbs}$ will have the potential to surpass and replace conventional mAbs currently used in many therapeutic areas.

\section{ACKNOWLEDGMENTS}

The authors thank all the team members of MAScIR, especially Dr. Zineb Qmichou for her help. This work was supported by a grant from the Ministry of High Education of Morocco.

\section{AUTHORS' CONTRIBUTIONS}

$\mathrm{HB}$ and FA defined the concept of the present review. NB and YA were involved in the acquisition of the data. $\mathrm{HB}, \mathrm{YC}$ and $\mathrm{HS}$ were involved in drafting and revision of the manuscript. All authors approved the final version of the manuscript.

\section{CONFLICTS OF INTEREST}

The authors declare no conflict of interest.

\section{REFERENCES}

Albrecht D, Winterflood CM and Ewers H (2015). Dual color single particle tracking via nanobodies. Methods Appl Fluoresc. 3(2): 024001.

Alibakhshi A, Kahaki FA, Ahangarzadeh S, Yaghoobi H, et al. (2017). Targeted cancer therapy through antibody fragments-decorated nanomedicines. J. Control Release. 268: 323-334.

Allegra A, Innao V, Gerace D, Vaddinelli D, et al. (2018). Nanobodies and cancer: current status and new perspectives. Cancer Invest. 36(4): 221-237.

Andersen DC and Krummen L (2002). Recombinant protein expression for therapeutic applications. Curr. Opin. Biotechnol. 13(2): 117-123.

Castel G, Heyd B and Tordo N (2009). Le phage display: une nouvelle arme pour la recherche antivirale. Virologie. 13(2): 93-102.

Castel G and Tordo N (2009). Nouvelles stratégies pour la conception de molécules antivirales. Rev. Francoph. des Lab. (417): 91-100.

Choi ML and Gandhi S (2018). Crucial role of protein oligomerization in the pathogenesis of Alzheimer's and Parkinson's diseases. FEBS J. doi:10.1111/febs.14587.

Comor L, Dolinska S, Bhide K, Pulzova L, et al. (2017). Joining the in vitro immunization of alpaca lymphocytes and phage display: rapid and cost effective pipeline for sdAb synthesis. Microb. Cell Fact. 16(1): 13.

Crameri R and Kodzius R (2001). The powerful combination of phage surface display of cDNA libraries and high throughput screening. Comb. Chem. High Throughput Screen. 4(2): 145-155.

Daly R and Hearn MT (2005). Expression of heterologous proteins in Pichia pastoris: a useful experimental tool in protein engineering and production. J. Mol. Recognit. 18(2): 119-138

DeFrancesco L (2017). 3Q17-Funding and partnership into overdrive, Nature Publishing Group. Nat. Biotechnol. 35 (2): 1005.

Dekempeneer Y, Keyaerts M, Krasniqi A, Puttemans J, et al. (2016). Targeted alpha therapy using short-lived alphaparticles and the promise of nanobodies as targeting vehicle. Expert Opin. Biol. Ther. 16(8): 1035-1047.

Desmyter A, Transue TR, Ghahroudi MA, Thi M-HD, et al. (1996). Crystal structure of a camel single-domain VH antibody fragment in complex with lysozyme. Nat. Struct. Biol. 3(9): 803-811.

Detalle L, Stohr T, Palomo C, Piedra PA, et al. (2016). Generation and characterization of ALX-0171, a potent novel therapeutic nanobody for the treatment of respiratory syncytial virus infection. Antimicrob. Agents Chemother. 60(1): 6-13. 
Dooley H, Flajnik MF and Porter AJ (2003). Selection and characterization of naturally occurring single-domain (IgNAR) antibody fragments from immunized sharks by phage display. Mol. Immunol. 40(1): 25-33.

Du J, LiX-Y, Hu H, Xu L, et al. (2018). Preparation and Imaging Investigation of Dual-targeted C 3 F 8-filled PLGA Nanobubbles as a Novel Ultrasound Contrast Agent for Breast Cancer. Sci. Rep. 8(1): 3887.

Dubois B, Feldman HH, Jacova C, Cummings JL, et al. (2010). Revising the definition of Alzheimer's disease: a new lexicon. Lancet Neurol. 9(11): 1118-1127.

Farka Z, Jurik T, Kovar D, Trnkova L, et al. (2017). Nanoparticle-based immunochemical biosensors and assays: recent advances and challenges. Chem. Rev. 117(15): 9973-10042.

Farrington GK, Caram-Salas N, Haqqani AS, Brunette E, et al. (2014). A novel platform for engineering blood-brain barrier-crossing bispecific biologics. FASEB J. 28(11): 4764-4778.

Flajnik MF, Deschacht N and Muyldermans S (2011). A case of convergence: why did a simple alternative to canonical antibodies arise in sharks and camels? PLoS Biol. 9(8): e1001120.

Fleetwood F, Devoogdt N, Pellis M, Wernery U, et al. (2013). Surface display of a single-domain antibody library on Gram-positive bacteria. Cell. Mol. Life Sci. 70(6): 1081-1093.

Frenken LG, Van der Linden RH, Hermans PW, Bos JW, et al. (2000). Isolation of antigen specific llama VHH antibody fragments and their high level secretion by Saccharomyces cerevisiae. J. Biotechnol. 78(1): 11-21.

Fridy PC, Li Y, Keegan S, Thompson MK, et al. (2014). A robust pipeline for rapid production of versatile nanobody repertoires. Nat. Methods. 11(12): 1253.

Ghahroudi MA, Desmyter A, Wyns L, Hamers R, et al. (1997). Selection and identification of single domain antibody fragments from camel heavy-chain antibodies. FEBS lett. 414(3): 521-526.

Greenberg AS, Avila D, Hughes M, Hughes A, et al. (1995). A new antigen receptor gene family that undergoes rearrangement and extensive somatic diversification in sharks. Nature. 374(6518): 168-173.

Griffiths K, Dolezal O, Parisi K, Angerosa J, et al. (2013). Shark variable new antigen receptor (VNAR) single domain antibody fragments: stability and diagnostic applications. Antibodies. 2(1): 66-81.

Guardiola S, Varese M, Sánchez-Navarro M, Vincke C, et al. (2018). Blocking EGFR Activation with Anti-EGF Nanobodies via Two Distinct Molecular Recognition Mechanisms. Angew Chem. Int. Ed. Engl. 57(42): 1384313847.

Hamers-Casterman C, Atarhouch T, Muyldermans S, Robinson G, et al. (1993). Naturally occurring antibodies devoid of light chains. Nature. 363(6428): 446-448.

Hassanzadeh-Ghassabeh G, Devoogdt N, De Pauw P, Vincke C, et al. (2013). Nanobodies and their potential applications. Nanomedicine. 8(6): 1013-1026.

Hemmer C (2015). Développement et utilisation de nanobodies dirigés contre le Grapevine fanleaf virus (GFLV) en lutte antivirale et comme biocapteur in planta. Doctoral thesis. Université de Strasbourg. Available at [file:///C:/Users/dell1/Downloads/Hemmer_Caroline_2015_ED414.pdf].

Huang L, Muyldermans S and Saerens D (2010). Nanobodies®: proficient tools in diagnostics. Expert Rev. Mol. Diagn. 10(6): 777-785.

Hussack G, Hirama T, Ding W, MacKenzie R, et al. (2011). Engineered single-domain antibodies with high protease resistance and thermal stability. PloS one. 6(11): e28218.

Kazemi-Lomedasht F, Behdani M, Bagheri KP, Habibi-Anbouhi M, et al. (2015). Inhibition of angiogenesis in human endothelial cell using VEGF specific nanobody. Mol. Immunol. 65(1): 58-67.

Klenerman D, Iljina M, Hong L, Horrocks M, et al. (2017). Nanobodies raised against monomeric a-synuclein inhibit fibril formation and destabilize toxic oligomeric species. BMC Biol. 15(1): 57.

Koch K, Kalusche S, Torres JL, Stanfield RL, et al. (2017). Selection of nanobodies with broad neutralizing potential against primary HIV-1 strains using soluble subtype C gp140 envelope trimers. Sci. Rep. 7(1): 8390.

Lauwereys M, Ghahroudi MA, Desmyter A, Kinne J, et al. (1998). Potent enzyme inhibitors derived from dromedary heavy-chain antibodies. EMBO J. 17(13): 3512-3520.

Mejias A, Garcia-Maurino C, Rodriguez-Fernandez R, Peeples ME, et al. (2017). Development and clinical applications of novel antibodies for prevention and treatment of respiratory syncytial virus infection. Vaccine. 35(3): 496-502.

Muyldermans S (2013). Nanobodies: natural single-domain antibodies. Annu Rev. Biochem. 82(1): 775-797.

Näätsaari L, Mistlberger B, Ruth C, Hajek T, et al. (2012). Deletion of the Pichia pastoris KU70 homologue facilitates platform strain generation for gene expression and synthetic biology. PloS One. 7(6): e39720.

Perez XA, Bressler AJ and Andrews AM (2007). Determining serotonin and dopamine uptake rates in synaptosomes using high-speed chronoamperometry. $1^{\text {st }}$ edn. Electrochemical Methods for Neuroscience. Bookshelf. US.

Pérol M and Arpin D (2011). Maintenance therapy in advanced non-small cell lung cancer: A new paradigm? Presse Med. 40(4): 404-414.

Platonova E, Winterflood CM, Junemann A, Albrecht D, et al. (2015). Single-molecule microscopy of molecules tagged with GFP or RFP derivatives in mammalian cells using nanobody binders. Methods. 88: 89-97.

Rader C and Barbas CF III (1997). Phage display of combinatorial antibody libraries. Curr. Opin. Biotechnol. 8(4): 503508.

Rahbarizadeh F, Ahmadvand D and Sharifzadeh Z (2011). Nanobody; an old concept and new vehicle for immunotargeting. Immunol. Invest. 40(3): 299-338.

Genetics and Molecular Research 19 (1): gmr18452 
Ren X, Yan J, Wu D, Wei Q, et al. (2017). Nanobody-based apolipoprotein E immunosensor for point-of-care testing. ACS Sens. 2(9): 1267-1271.

Roberts RF, Wade-Martins R and Alegre-Abarrategui J (2015). Direct visualization of alpha-synuclein oligomers reveals previously undetected pathology in Parkinson's disease brain. Brain. 138(6): 1642-1657.

Roovers RC, Laeremans T, Huang L, De Taeye S, et al. (2007). Efficient inhibition of EGFR signalling and of tumour growth by antagonistic anti-EGFR Nanobodies. Cancer Immunol. Immunother. 56(3): 303-317.

Rothbauer U, Zolghadr K, Tillib S, Nowak D, et al. (2006). Targeting and tracing antigens in live cells with fluorescent nanobodies. Nat. Methods. 3(11): 887-889.

Ryckaert S, Pardon E, Steyaert J and Callewaert N (2010). Isolation of antigen-binding camelid heavy chain antibody fragments (nanobodies) from an immune library displayed on the surface of Pichia pastoris. J. Biotechnol. 145(2): 93-98.

Saerens D, Ghassabeh GH and Muyldermans S (2008). Single-domain antibodies as building blocks for novel therapeutics. Curr. Opin Pharmacol. 8(5): 600-608.

Safder I, Khan S, Islam I-u and Kazim M (2018). Pichia pastoris expression system: a potential candidate to express protein in industrial and biopharmaceutical domains. Biomed. Lett. 4(1): 1-14.

Shemi A, Khvalevsky EZ, Gabai RM, Domb A, et al. (2015). Multistep, effective drug distribution within solid tumors. Oncotarget. 6(37): 39564-39577.

Siontorou CG (2013). Nanobodies as novel agents for disease diagnosis and therapy. Int. J. Nanomedicine. 8: 42154227.

Souriau C, Lefranc M and Weill M (1998). Présentation a la surface de phages filamenteux: les multiples applications du phage display. Med. Sci. 14(3): 300-9.

Streltsov VA, Carmichael JA and Nuttall SD (2005). Structure of a shark IgNAR antibody variable domain and modeling of an early-developmental isotype. Protein Sc. 14(11): 2901-2909.

Thomassen YE, Meijer W, Sierkstra L and Verrips CT (2002). Large-scale production of VHH antibody fragments by Saccharomyces cerevisiae. Enzyme Microb. Technol. 30(3): 273-278.

Traenkle B and Rothbauer U (2017). Under the microscope: Single-domain antibodies for live-cell imaging and superresolution microscopy. Front Immunol. 8: 1030.

Transue TR, De Genst E, Ghahroudi MA, Wyns L, et al. (1998). Camel single-domain antibody inhibits enzyme by mimicking carbohydrate substrate. Proteins Struct. Funct. Genet. 32(4): 515-522.

Ulrichts H, Silence K, Schoolmeester A, de Jaegere P, et al. (2011). Antithrombotic drug candidate ALX-0081 shows superior preclinical efficacy and safety compared with currently marketed antiplatelet drugs. Blood. 118(3): 757765.

Vaidyanathan G, McDougald D, Choi J, Koumarianou E, et al. (2016). Preclinical evaluation of 18F-labeled anti-HER2 nanobody conjugates for imaging HER2 receptor expression by immuno-PET. J. Nucl. Med. 57(6): 967-973.

Van Audenhove I and Gettemans JJE (2016). Nanobodies as versatile tools to understand, diagnose, visualize and treat cancer. EBioMedicine. 8: 40-48.

Van Bockstaele F, Holz J-B and Revets H (2009). The development of nanobodies for therapeutic applications. Curr. Opin. Investig Drugs. 10(11): 1212-1224.

Vaneycken I, D'huyvetter M, Hernot S, De VosJ, et al. (2011). Immuno-imaging using nanobodies. Curr. Opin. Biotechnol. 22(6): 877-881.

Vaneycken I, Devoogdt N, Van Gassen N, Vincke C, et al. (2011). Preclinical screening of anti-HER2 nanobodies for molecular imaging of breast cancer. FASEB J. 25(7): 2433-2446.

Vanlandschoot P, Stortelers C, Beirnaert E, Ibañez LI, et al. (2011). Nanobodies®: new ammunition to battle viruses. Antiviral Res. 92(3): 389-407.

Wang D, Yang S, Yin S, Shang Y, et al. (2015). Characterization of single-domain antibodies against Foot and Mouth Disease Virus (FMDV) serotype O from a camelid and imaging of FMDV in baby hamster kidney-21 cells with single-domain antibody-quantum dots probes. BMC Vet. Res. 11(1): 120.

Wang Y, Fan Z, Shao L, Kong X, et al. (2016). Nanobody-derived nanobiotechnology tool kits for diverse biomedical and biotechnology applications. Int. J. Nanomedicine. 11: 3287-3303.

Wesolowski J, Alzogaray V, Reyelt J, Unger M, et al. (2009). Single domain antibodies: promising experimental and therapeutic tools in infection and immunity. Med. Microbiol. ImmunoL. 198(3): 157-174.

Wolfson W (2006). Ablynx makes nanobodies from llama bodies. Chem. Biol. 13(12): 1243-1244.

Yan J, Wang P, Zhu M, Li G, et al. (2015). Characterization and applications of Nanobodies against human procalcitonin selected from a novel naïve Nanobody phage display library. J. Nanobiotechnology. 13(1): 33.

Zhou Z, Vaidyanathan G, McDougald D, Kang CM, et al. (2017). Fluorine-18 labeling of the HER2-targeting singledomain antibody 2Rs15d using a residualizing label and preclinical evaluation. Mol. Imaging. Biol. 19(6): 867-877.

Zou T, Dembele F, Beugnet A, Sengmanivong L, et al. (2015). Nanobody-functionalized PEG-b-PCL polymersomes and their targeting study. J. Biotechnol. 214: 147-155. 